\title{
A MULTIDIMENSIONALIDADE DA IMAGEM DE PREÇO DE PRODUTO: UM ESTUDO
} COM A IMAGEM DE PREÇO DE VESTUUÁRIO

DEONIR DE TON

Doutor em Administração pela Escola de Administração da Universidade Federal do Rio Grande do Sul (UFRGS).

Professor e pesquisador do Centro de Ciências da Administração da Universidade de Caxias do Sul (CCAD-UCS).

Rua Francisco Getúlio Vargas, 1.130, PPGA, Bloco F, Petrópolis, Caxias do Sul - RS - Brasil - CEP 95070-560

E-mail:dtoni2@ucs.br

\section{JOSÉ AFONSO MAZZON}

Doutor em Administração pela Faculdade de Economia, Administração e Contabilidade da Universidade de São Paulo (FEA-USP).

Professor titular da Faculdade de Economia, Administração e Contabilidade da Universidade de São Paulo.

Avenida Professor Luciano Gualberto, 908, sala E-187, Cidade Universitária, São Paulo - SP - Brasil - CEP 05508-010

E-mail: jamazzon@usp.br

\section{GABRIEL SPERANDIO MILAN}

Doutor em Engenharia de Produção pelo Departamento de Engenharia de Produção da Universidade Federal do Rio Grande do Sul (UFRGS).

Professor e pesquisador do Centro de Ciências da Administração da Universidade de Caxias do Sul (CCAD-UCS).

Rua Francisco Getúlio Vargas, 1.130, PPGA, Bloco F, Petrópolis, Caxias do Sul - RS - Brasil - CEP 95070-560

E-mail:gsmilan@ucs.br 


\section{RESUMO}

A compreensão das imagens formadas por diversos públicos sobre o preço constitui um importante elemento para o direcionamento de estratégias de posicionamento de produtos no mercado, bem como do composto de comunicação para melhor apoiar a performance do preço dos produtos. Esta pesquisa teve por objetivo, em primeiro lugar, identificar, a partir da revisão da literatura, as dimensões que melhor explicam como a imagem de preço de produtos pode ser formada e, em segundo, verificar como elas se configuram na imagem mental de uma população-alvo. Os resultados sugerem que a imagem de preço de produtos, compreendida como uma variável latente e multidimensional, pode ser configurada a partir de seis dimensões: funcional, emocional, simbólica, de justiça, axiomática e social. Esses atributos associados ao valor percebido retratam o benefício ou sacrifício de cada atributo relacionado à dimensão analisada. Com base no método de configuração de imagem (MCI), foi possível estudar como essas dimensões se configuram em uma amostra de 337 estudantes de graduação, a partir de uma "peça de vestuário ou um acessório", cujo preço aproximado de venda nas lojas é de R $\$ 500,00$. Os resultados apresentam 627 citações dos respondentes, das quais $68 \%$ estão relacionadas aos benefícios percebidos. Além disso, as dimensões mais salientes foram as seguintes: funcional (relacionada à qualidade percebida), de justiça (verificada a partir da relação custo versus benefício) e simbólica (identificada a partir do status e do luxo). Para melhor visualização dos resultados, um gráfico e um quadro explicativo apresentam como a imagem de preço do produto pode ser configurada para auxiliar no melhor direcionamento de estratégias de comunicação e apreçamento dos produtos.

\section{PALAVRAS-CHAVE}

Imagem de preço. Valor percebido. Configuração de imagens. Multidimensionalidade da imagem. Método de configuração de imagem. 


\section{INTRODUÇ்̃̃}

A definição de prioridades de pesquisa pelo Marketing Science Institute (MSI), para o biênio 2006-2008, indicou a pouca ênfase aos estudos a respeito do preço, já que o destaque está em temas como inovação, métricas e associados à lealdade. Estudos de preço permanecem ainda uma área pouco estudada no marketing, e o preço é o elemento do mix do marketing mais negligenciado (Avlonitis \& Indounas, 2006).

O preço é considerado uma das mais importantes variáveis da gestão mercadológica. Sendo assim, vários esforços têm sido dirigidos para analisar a percepção do preço dos produtos e a influência dele na decisão de compra (Zeithaml, I988; Zielke, 2006, 20II; Bolton, Warlop, \& Alba, 2003). Do ponto de vista gerencial, o preço é considerado o elemento mais poderoso no mix do marketing e também um dos mais flexíveis, apresentando um forte impacto nos resultados de marketing no curto prazo (Simon, Bilstein, \& Luby, 2008).

Como a imagem associada ao preço é um construto complexo, multidimensional, ainda não está devidamente definida na área de estudos do marketing (Zielke, 2006, 2010). Essa associação é formada a partir do valor relacionado à percepção de benefícios e sacrifícios, para os quais a apreensão do cliente (ou consumidor) se dá nas dimensões dos níveis funcional, simbólico, de justiça, emocional, social e axiomático. Destaca-se ainda que o uso da expressão imagem de preço está associado à percepção, por parte do consumidor, das características do valor para si como um todo (benefícios versus sacrifícios) e não apenas do seu componente monetário.

Para tanto, esta pesquisa tem dois objetivos-alvo que justificam sua realização: o primeiro é identificar, a partir da revisão da literatura, as dimensões que melhor explicam como a imagem de preço de produto pode ser formada; o segundo é testar, a partir de um estudo exploratório, como essas dimensões se configuram na imagem mental de uma amostra-alvo. Dessa forma, inicialmente, fez-se uma revisão da literatura identificando as principais dimensões que auxiliam a entender a formação de uma imagem de preço, e, em seguida, adotou-se uma abordagem exploratória a partir de uma derivação do Método de configuração de imagem - MCI (De Toni, 2009; Schuler, De Toni, \& Milan, 20I4) explorando a formação da imagem do preço de vestuário em uma amostra de 337 estudantes de graduação de uma universidade da Região Sul do Brasil. Nesse sentido, buscou-se identificar os atributos formadores da imagem de preço de "peça de vestuário ou um acessório", cujo preço aproximado de venda nas lojas é de $\mathrm{R} \$ 500,00$. A partir dos 37 atributos identificados e da análise de conteúdo, verificaram-se os atributos que fazem parte do núcleo das representações do 
preço do vestuário e como estão organizados no que se refere às dimensões e ao benefício ou sacrifício percebido.

Das 627 citações dos respondentes, $68 \%$ estão relacionadas ao benefício percebido. Assim, os resultados indicam que a imagem de vestuário no preço informado está fortemente associada ao benefício funcional (qualidade e marca) e benefício de justiça (custo versus benefício) e sacrifício emocional e de justiça (caro, absurdo). De modo que, apesar de os pesquisados considerarem o preço de uma peça de vestuário alto, o benefício (qualidade e marca) compensaria o sacrifício (ser cara).

Por fim, esses atributos estão dispostos em um gráfico e um quadro explicativo que apresentam, de forma detalhada, os resultados da configuração da imagem do preço do vestuário e/ou acessório, bem como as ações estratégicas que poderiam ser desenvolvidas para trabalhar sua imagem junto ao público. Entender como o consumidor processa o preço de um produto é uma discussão relevante tanto no meio acadêmico quanto no gerencial. Por conseguinte, a partir do entendimento de como as imagens de preço podem ser configuradas, os gestores poderão melhor direcionar suas ações estratégicas de comunicação e apreçamento dos produtos.

\section{IMAGEM: CONCEITOS E PRESSUPOSTOS}

As imagens constituem um dos materiais intelectuais mais importantes do homem, sendo capazes de influenciar e direcionar o comportamento das pessoas. Desse modo, a compreensão das imagens que os diversos públicos formam sobre preço constitui um importante trunfo para o direcionamento de estratégias de posicionamento de produtos no mercado, bem como do composto de comunicação para melhor apoiar a performance do preço dos produtos (De Toni \& Mazzon, 2013).

Zaltman (2000) afirma que, devido à complexidade do comportamento do consumidor, esse fenômeno necessita ser abordado de forma multidisciplinar, de forma holística, em que corpo, mente, emoções e espírito sejam considerados igualmente e em inter-relação. Um melhor entendimento sobre o homem passa pela compreensão de sua totalidade, não apenas de algum aspecto particular.

Dentre as diferentes perspectivas do entendimento de como as imagens estão organizadas na memória, a teoria do núcleo desponta como uma alternativa importante para entender a configuração da imagem na memória humana. Essa teoria sugere que o homem organiza e processa as informações de forma dinâmica e evolutiva em torno de um núcleo e de um conjunto de elementos 
periféricos (Abric, I984; Sá, I996). Segundo o pesquisador francês Jean Claude Abric (I984, I998a), toda e qualquer representação é organizada em torno de um núcleo, constituído de um ou mais elementos que dão à representação o seu significado, e que ocupa, na estrutura dessa representação, uma posição privilegiada. Esse núcleo é determinado pela natureza do objeto representado, pelo tipo de relação que os indivíduos mantêm com esse objeto e pelo conjunto de valores e normas compartilhados pelo grupo ao qual pertencem. Todo o pensamento necessita, para garantir a identidade e a continuidade do grupo social a que se refere, de certo número de crenças, coletivamente engendradas e historicamente determinadas, que sejam "inegociáveis". Isto é, que não possam ser postas em questão, por constituírem o fundamento do modo de vida e do sistema de valores do grupo. Sendo assim, só é possível afirmar que dois ou mais grupos têm a mesma representação de um objeto, se são homogêneos ou não, se eles partilham o mesmo núcleo (Alves Mazzotti, 2002).

O núcleo é determinado, em parte, pela natureza do objeto representado e, em parte, pela relação que o sujeito, ou um grupo de pessoas, mantém com esse objeto. Por isso, o núcleo se constitui como um subconjunto da representação, composto de um ou mais elementos, cuja ausência desestruturaria a representação ou lhe daria uma significação completamente diferente (Sá, I996).

Segundo Abric (I998a, I998b), o núcleo desempenha três funções essenciais: geradora, que cria ou transforma uma representação; organizadora, que determina a natureza das ligações entre os elementos de uma representação; e estabilizadora, que mantém os conceitos centrais e resiste às mudanças. Em acréscimo, Alves Mazzotti (2002) apresenta três elementos centrais da composição das representações: o valor simbólico, que é a relação da representação com o objeto e que não pode ser dissociada do objeto da representação sob pena de perder a significação; o poder associativo, que está relacionado à polissemia das noções centrais e de sua capacidade de se associar a outros elementos da representação; e a saliência, que está ligada tanto ao valor simbólico quanto à polissemia e às cognições centrais, que ocupam um lugar privilegiado no discurso, sendo evocadas mais frequentemente que as demais. No entanto, como esclarece Abric (como citado em Alves Mazzotti, 2002), a dimensão quantitativa não é por si só determinante da centralidade de um elemento. Há também que se considerar sua dimensão qualitativa, isto é, se esse elemento é ou não aquele que dá sentido à representação. Isso torna necessário o teste da centralidade, o qual se baseia justamente na verificação do caráter inegociável dos elementos mais salientes.

Os atributos que compõem o núcleo são marcados pela memória coletiva e são estáveis e resistentes à mudança. Sua função é gerar significação para as imagens. Em torno do sistema central da imagem, há o sistema periférico, 
constituído pelos atributos mais flexíveis, sensíveis ao contexto imediato. Sua função é permitir a adaptação à realidade, bem como a diferenciação do conteúdo e a proteção ao sistema central. Os sistemas periféricos estão mais próximos das práticas do cotidiano e sujeitos às mudanças (Sá, I996). Enquanto o núcleo é historicamente marcado, coerente, consensual e estável, o sistema periférico é adaptativo, flexível e relativamente heterogêneo quanto ao conteúdo (Abric, I993).

Nesse horizonte, Reynolds e Gutman (I984) identificam a imagem como um conjunto de significados hierarquicamente organizados e armazenados na memória, cuja identificação se dá a partir da rede de relacionamentos entre esses significados. Portanto, é possível entender que as imagens estão organizadas como uma rede de significados, ou esquemas associados, e organizadas em torno de alguns elementos centrais que são socialmente aceitos e compartilhados. Consoante a isso, a partir da revisão da literatura sobre a organização das imagens na memória dos indivíduos (nesse caso, consumidores), percebe-se que as pessoas organizam suas imagens em torno de alguns conceitos centrais, que vão dar significado ao objeto em análise e que compõem o núcleo de suas representações.

\section{PREÇO E SEUS IMPACTOS NAS DECISÕES ESTRATÉGICAS}

A partir da revisão da literatura, identificou-se que há uma carência de estudos relacionados ao preço, o qual é bastante negligenciado (Avlonitis \& Indounas, 2007). Entretanto, o estudo do preço não pode ser negligenciado pela academia, pois, seja ele considerado de forma independente ou conjuntamente com uma política ou estratégia de produto, exerce forte influência no comportamento de compra, bem como no posicionamento e nos resultados mercadológicos da empresa (Theodoridis \& Chatzipanagiotou, 2009).

Em uma perspectiva de marketing, numerosos estudos têm sido feitos visando avaliar o papel do preço no processo decisório de aquisição de bens e serviços, não apenas no mercado consumidor (Avlonitis \& Indounas, 2007; Shipley \& Jobber, 200I), mas também no mercado industrial e naqueles ligados à distribuição (revendas) (Monroe, I990; Nagle \& Holden, 2003), dentro das estratégias de marketing business-to-business (B2B) ou business-to-consumer $\left(\mathrm{B}_{2} \mathrm{C}\right)$, respectivamente. A complexidade e a multidimensionalidade que caracterizam as decisões de preço sob o ponto de vista organizacional emergem, ainda, de diferentes situações específicas, tais como dos níveis de demanda 
do mercado, níveis de controle do preço pelo Estado e estágios do ciclo de vida dos diferentes produtos e/ou serviços ofertados pelas empresas (Avlonitis, Indounas, \& Gounaris, 2005). A mensuração da imagem de preço de produto desponta como um elemento que os gestores podem utilizar para melhorar suas estratégias de marketing ou mais especificamente suas estratégias de precificação. Entender o preço a partir da percepção do consumidor pode exigir, então, novas metodologias e uma reavaliação das práticas atuais de formação e definição de preços.

Observa-se que as reações do consumidor às diferentes estratégias das empresas não são puramente racionais, mas dirigidas por aspectos específicos do comportamento, tais como as suas percepções (por exemplo, ligadas às imagens formadas) e as suas preferências. Entender a percepção do consumidor em relação aos preços pode ser o diferencial de uma empresa em relação aos seus competidores (Kim, Natter, \& Spann, 2009). Estratégias de precificação envolvendo o consumidor possibilitam que este tenha uma maior percepção de justiça e de satisfação do que quando a empresa ajusta seus preços puramente pelos seus custos (Haws \& Bearden, 2006).

Para Monroe (I990), o preço é um elemento fundamental do mix de marketing, pois é o único a produzir receita, enquanto os demais elementos geram dispêndio de capital (ou investimentos). Assim, as decisões acerca dos preços contribuem para determinar o valor do produto para o consumidor e têm um papel central na construção da imagem da empresa e de sua oferta (Urbany, 200I). O preço não é simplesmente o custo do bem somado ao lucro. É a soma de valores de um produto e/ou serviço, os quais podem ser tanto tangíveis (durabilidade e performance) quanto intangíveis (marca, prestígio e status). Quanto maior for o valor que a empresa entrega para seus consumidores, maiores serão os níveis de preço que ela, em tese, poderá praticar (Lancioni, ı988; Theodoridis \& Chatzipanagiotou, 2009).

Há dois pré-requisitos para tornar o apreçamento proativo um sucesso. $\mathrm{O}$ primeiro é a necessidade de entender como o preço trabalha, quais seus impactos nos fornecedores, no pessoal de venda, nos distribuidores, competidores e clientes ou consumidores. O segundo é a identificação de como o cliente percebe o preço e suas mudanças. Empresas proativas na formação de preço devem aprender como seus clientes percebem o preço do produto ou serviço ofertado e como essa imagem influencia sua percepção de valor e sua intenção de compra. A relação entre o preço e a percepção de valor do produto, serviço ou marca para o consumidor é que determina as decisões de compra (Monroe, I990). 


\section{A MULTIDIMENSIONALIDADE DA IMAGEM DE PREÇO}

Muitos dos estudos sobre imagem de preço não capturam o domínio completo desse tema, porque predominantemente mensuram tão somente a dimensão cognitiva da percepção do preço (Zielke, 20II). A imagem de preço pode ser definida como variável latente e multidimensional que consiste numa convicção subjetiva e emocional associada a fatores relacionados com o preço de um produto e/ou serviço (Zielke, 2006, 20II).

A literatura de comportamento de preço revela um viés cognitivo. Grande parte das pesquisas está concentrada no preço como um fenômeno cognitivo. Dessa forma, o preço de referência, a inferência preço-qualidade, o julgamento de valor para o dinheiro, a percepção de justiça de preço e o conhecimento de preço são exemplos de direcionamentos cognitivos para o comportamento do preço (Peine, Heitmann, \& Herrmann, 2009). No entanto, sentimentos de justiça e injustiça com relação a um preço são manifestações não cognitivas dos consumidores que refletem mudanças no comportamento de compra (Peine et al., 2009; Xia, Monroe, \& Cox, 2004). O consumidor julga o preço a partir de suas normas internas, representadas por uma combinação de experiências do passado, do presente e de expectativas futuras (projeções) (Tsiros \& Hardesty, 20Io).

A partir dos estudos de Zielke (2006, 20I0, 20II), Mittal, Holbrook, Beatty, Raghuber e Woodside (2007), Schuler, De Toni, Milan, Panizzon e Larentis (20I0), Sweeney e Soutar (200I) e De Toni e Mazzon (2013), foram identificadas II dimensões relacionadas à percepção dos benefícios do produto e do sacrifício exigido para sua aquisição. Tais dimensões se referem aos aspectos de natureza física/material, emocional, de autoestima, funcional, de poder, social, de justiça, simbólica, visionária, axiomática e teleológica. Com base na análise dos conceitos associados a cada dimensão, foi possível realizar um refinamento delas, assegurando que cada dimensão fosse agrupada apropriadamente, eliminando dimensões que não apresentassem relevância para o presente estudo. A partir disso, identificaram-se seis dimensões determinantes da imagem de preço de produto: funcional, emocional positiva, emocional negativa, simbólica, de justiça, axiomática e social. A seguir, apresenta-se o conceito associado a cada uma dessas dimensões.

\subsection{DIMENSÃO FUNCIONAL}

$\mathrm{O}$ aspecto de funcionalidade da percepção de preço está relacionado à percepção da qualidade do produto e/ou serviço (Lichtenstein, Ridgway, \& Netemeyer, 
I993; Yeung \& Soman, 2007; Zielke, 2010). Para Zeithaml (I988), a percepção de qualidade de um produto, em específico, pode estar relacionada tanto a fatores intrínsecos quanto a extrínsecos. Dicas (pistas ou evidências) intrínsecas estão fortemente relacionadas às propriedades físicas do produto, enquanto as extrínsecas estão relacionadas aos atributos externos ao produto, não constituindo parte deste.

O preço como um atributo extrínseco da qualidade do produto apresenta uma maior importância quando:

- em uma compra inicial, os atributos intrínsecos (atributos específicos do produto, como frescor e gosto ou sabor de um suco) não estão disponíveis;

- a avaliação de uma sugestão intrínseca requer mais esforço e tempo, e o consumidor não tem interesse nisso;

- a qualidade é difícil de ser previamente avaliada (experiência e crença no produto) (Zeithaml, I988). Quando as dicas intrínsecas do produto estão acessíveis, com nome da marca, que dá evidências da reputação ou da credibilidade da empresa, e também quando o nível de comunicação induz à confiança na empresa ou em sua marca, o consumidor pode preferir essas sugestões ao preço (Monroe, I990; Nagle \& Holden, 2003; Zeithaml, I988).

Entretanto, quando informações intrínsecas são escassas ou não suficientemente úteis, informações extrínsecas podem ser úteis para avaliar a qualidade de um produto (Chernev, 2006; Miyazaky, Grewall, \& Goodstein, 2005). Na ausência de elementos intrínsecos, o consumidor tende a utilizar dicas extrínsecas - por exemplo, preço, marca ou país de origem - como aspectos indicadores da qualidade do produto (Ting, 20I2). Assumindo que preço mais alto justifica melhor qualidade e maior valor percebido do produto, o valor funcional estará normalmente associado ao construto qualidade e à relação desta com a percepção de preço (Costa, 2007; Sweeney \& Soutar, 200I).

Dessa forma, o uso do preço como um indicador funcional da qualidade de um produto depende: I. da disponibilidade de outras indicações ou informações para poder avaliar a qualidade do produto; 2 . da variação de preço entre marcas, dentro de uma classe de produtos; 3. do nível de consciência de preço do consumidor; 4 . da habilidade do consumidor em perceber a variação de qualidade em um grupo de produtos; e 5. da percepção de que a baixa qualidade implica o risco de uma perda. Logicamente, essa comparação de qualidade é mais intuitiva e não é um fenômeno facilmente mensurável quando se comparam diferentes marcas. Nesse sentido, emerge o conceito de "melhor valor" (best value), em que o consumidor combina dicas de preço e de qualidade para chegar à escolha que melhor preencherá as suas expectativas ou exigências (Guiltinan, 2000). 


\subsection{DIMENSÃO EMOCIONAL}

O fenômeno da emoção, fartamente estudado na psicologia, tem recebido acentuada atenção em pesquisas recentes sobre comportamento do consumidor (Aaker, Drolet, \& Griffin, 20II; Bagozzi \& Dholakia, I999; Cohen, Pham, \& Andrade, 2008; Laros \& Steenkamp, 2003). Porém, são poucos os estudos que mencionam o papel da emoção na percepção do consumidor acerca dos preços (Peine et al., 2009; Zielke, 20II). Vale destacar que os sentimentos de prazer, angústia, raiva ou interesse estão presentes na avaliação, tanto do valor dos produtos para um consumidor quanto do sacrifício que deverá fazer para adquiri-los (Zielke, 20IO).

Bagozzi e Dholakia (I999) definem emoção como um estado mental de prontidão que surge de uma avaliação cognitiva de eventos e de pensamentos que são relevantes para o indivíduo. No caso desta pesquisa, a dimensão emocional deriva de um sentimento ou estado afetivo que o preço de um produto pode gerar. A emoção é uma experiência interna, um sentimento que motiva, organiza e guia as imagens e, consequentemente, as ações (O'Neill \& Lambert, 200I). As emoções são reações ao que acontece na vida das pessoas (Lazarus, I99I). De acordo com os estudos de Goleman (2007), Lazarus (I99I), Ledoux (200I), Richins (I997) e Zielke (2010), as principais categorias de emoções podem ser agrupadas em:

- ira: raiva, fúria, indignação, aborrecimento, hostilidade, ódio, revolta, descontentamento;

- medo: ansiedade, apreensão, nervosismo, preocupação, cautela, inquietação, pavor, susto, fobia;

- tristeza: sofrimento, mágoa, desânimo, melancolia, solidão, desamparo, desespero, desgosto, depressão;

- vergonha: culpa, mágoa, remorso, humilhação, arrependimento;

- inveja: ciúmes, querer alguma coisa que outro tem;

- esperança: temer o pior, mas ansiar o melhor, acreditar no futuro, otimismo;

- prazer: felicidade, alegria, alívio, diversão, emoção, satisfação, humor, euforia, realização, entusiasmo, excitação;

- orgulho: amor próprio, valorização social, realização;

- amor: aceitação, altruísmo, amizade, confiança, afinidade, dedicação, paixão, compaixão;

- surpresa: choque, espanto, maravilha;

- nojo: desprezo, desdém, antipatia, repugnância, aversão;

- paz: calma, tranquilidade. 
Assim sendo, as emoções positivas (por exemplo, alegria e esperança) estão associadas ao comportamento do consumidor proativo, de aproximação ou de ativação. Já as emoções negativas (por exemplo, medo e nojo) estão associadas a um comportamento passivo, de evitação ou de inibição (Peine et al., 2009; Zielke, 20II).

\subsection{DIMENSÃO JUSTIÇA}

A justiça de preço corresponde a um julgamento realizado pelo comprador sobre o preço do vendedor. Refere-se ainda a uma comparação entre o preço julgado e um padrão de mercado, e, nessa comparação, é possível identificar a igualdade, a vantagem ou a desvantagem percebida pelo consumidor (Munnukka, 2006; Xia et al., 2004). Embora a justiça de preço seja um conceito difícil de ser definido, a percepção de preço justo é parte de um amplo julgamento do mérito geral de uma negociação, e a reputação da empresa, o grau de relacionamento existente e a satisfação do consumidor afetam a percepção de justiça relacionada ao comprador (Haws \& Bearden, 2006).

Para Bolton et al. (2003), a justiça de preço é um julgamento sobre o resultado de um processo, obtido por meio da avaliação ante um padrão razoável, justo e aceitável. O aspecto cognitivo dessas definições indica que julgamentos sobre a justiça relacionados ao preço envolvem a comparação a um respectivo padrão, referência ou norma vigente (Fernandes \& Slongo, 2007). O consumidor usa o preço passado, de diferentes períodos de tempo, para formar suas expectativas e tomar suas decisões de compra ou consumo (Yuan \& Han, 20II). Isso posto, tem-se que a avaliação de (in)justiça é feita por meio da comparação de uma referência, que pode ser proveniente de "uma outra pessoa, um grupo de pessoas, uma organização ou o próprio indivíduo em relação à sua experiência no passado" (Monroe \& Lee, I999, p. 2I4).

Xia et al. (2004) indicam quatro fatores que influenciam a percepção de justiça no preço. O primeiro é a similaridade das transações, quando os consumidores percebem duas transações comerciais como similares, mas em uma o preço é maior do que em outra. Nesse caso, haverá uma percepção de que o preço é injusto. O segundo é a atribuição de culpa ou a não compreensão do motivo pelo qual a empresa realizou alguma alteração de preço, denotando uma situação de injustiça percebida. O terceiro fator é a confiança entre o cliente e a empresa derivada de relacionamentos. Quanto maior a confiança, maior a percepção de justiça no preço. $\mathrm{O}$ quarto fator corresponde às crenças do consumidor sobre as normas de trocas comerciais. Quanto maior a percepção de existência de regras comerciais adequadas, satisfatórias, maior a sensação de justiça no preço. Além 
disso, Kukar-Kinney, Xia e Monroe (2007) identificaram que quanto mais justo é um preço, maiores são as intenções de (re)compra de um indivíduo, o que reforça a suposição de que maiores níveis de injustiça ligados ao preço poderão fazer com que o consumidor busque outras alternativas de compra, trocando de marca ou de fornecedor. Portanto, a percepção de injustiça diminui a intenção de compra. Já a percepção de justiça no preço constitui uma dimensão-chave de influência no comportamento de compra do consumidor e, consequentemente, na formação das estratégias do negócio (Campbell, I999; Huangfu \& $\mathrm{Zhu}$, 20I2).

\subsection{DIMENSÃO AXIOMÁTICA}

Vários campos de estudo do comportamento humano se interessaram pelos princípios e valores pessoais que regem a vida dos indivíduos. É um nível ligado ao sentido da existência de uma pessoa (significado da vida) e à sua percepção de propósito e de valores e princípios. Os valores funcionam como um direcionamento prescritivo ou prospectivo nas convicções sobre o modo de conduzir a vida (Kahle \& Kennedy, I988). Vinson, Scott e Lamont (I977) sugerem, para o entendimento dos valores pessoais, dentro do contexto do marketing, que se considerem três níveis de abstração em uma estrutura hierárquica axiomática.

O primeiro, mais inclusivo e genérico, é o nível global de valores, considerado como o pilar central dos valores de um indivíduo, formado por crenças duradouras que guiam seus julgamentos, decisões e atos nas mais variadas situações de vida. O segundo é o nível de valores específicos por área, que trata dos valores que as pessoas adquirem na experiência de situações específicas de suas vidas, com referência a certos ambientes e domínio de atividades. Os indivíduos adquirem valores especificamente ligados às transações econômicas, a partir da vivência sequencial de trocas e das experiências de consumo; adquirem valores sociais por meio das vivências familiares e grupais, e, assim, nos vários campos de atividade com os quais interagem, o que leva as pessoas a acumular experiências. O terceiro nível de valores diz respeito às crenças descritivas e avaliativas, por meio das quais os indivíduos avaliam produtos e/ou serviços, em seu processo de decisão de compra e consumo, segundo o que os autores consideram como atributos desejáveis para um determinado bem (produto).

\section{4 - 5 DIMENSÃO SIMBÓLICA}

Um indivíduo, ao comprar um produto, também leva em conta seus atributos simbólicos, ou seja, aquilo que este representa para ele e para os outros 
com quem interage (Dichter, I985; Levy, I98I). Dobni e Zinkhan (I990) e Stern, Zinkhan e Jaju (200I) realizaram uma importante revisão dos diferentes conceitos de imagem de produto e de marca nos últimos 30 anos e concluíram que as pessoas compram objetos não somente pelo que eles podem fazer, mas principalmente pelo que significam. As coisas que as pessoas compram têm um significado pessoal e social, além de suas funções utilitárias. Segundo Levy (I98I), os atributos simbólicos são tão importantes quanto os atributos funcionais. É preciso considerar ainda que a imagem de preço é uma interpretação das informações recebidas, um conjunto de inferências e de reações sobre o produto e seus atributos associados. Portanto, a formação da imagem não depende apenas das mensagens racionalmente emitidas na estratégia de comunicação das empresas, mas também da forma como o consumidor vai recriar o significado das mensagens que recebe dos meios ou canais de comunicação (Dichter, I985; Levy, I98I; Martineau, I958).

O principal elemento do simbolismo de um produto e/ou serviço está relacionado ao sentimento de poder ou da falta deste. Tal percepção pode promover um maior desejo de adquirir, por exemplo, produtos associados com status ou com o reconhecimento, levando à propensão de pagar mais por esse tipo de produto (Rucker \& Galinsky, 2008). O preço pago pelo consumidor ao realizar uma compra pode representar seu poder, sua posição social sua sofisticação. $\mathrm{Ou}$, em contraposição, pode representar sua fraqueza, seu desleixo ou seu mau gosto. Pode representar ideologias consumistas e de moda ou ainda ideologias imbuídas de valor social. O símbolo de status de um produto pode não estar diretamente relacionado ao seu valor monetário. Mesmo um produto relativamente acessível (por exemplo, gravata de seda ou uma caneta de executivo) pode ter uma forte associação com status. Similarmente, mesmo um produto com um preço mais elevado (por exemplo, um automóvel) pode não ter, necessariamente, uma associação com status (Rucker \& Galinsky, 2008).

\section{6 DIMENSÃO SOCIAL}

É bastante conhecida, no marketing, a "atitude de preço" (Zielke, 2006, 20I0) representando uma forma de inserção ou de participação dos indivíduos em um grupo social. Faz parte do processo de socialização do indivíduo desenvolver atitudes de compra convenientes para o meio social onde se coloca, sendo o nível de preço um dos fatores mais salientes desse contexto (Sweeney, Soutar, \& Johnson, I999). O consumidor percebe, antes mesmo de entrar no ponto de venda, qual é o nível esperado de preço para determinados dos produtos e que postura de compra é esperada dele dentro da loja (Galhanone, 2008). Na 
dimensão social do preço, o indivíduo se preocupa principalmente com o que as outras pessoas pensam sobre ele e naquilo que os outros compram, usam ou consomem, aspectos que influenciam suas decisões de aquisição de bens e/ou de serviços (Bearden, Netemeyer, \& Teel, I989; Lennox \& Wolfe, I984).

Segundo Sheth, Newman e Gross (I99I) e Costa (2007), o valor social se refere à utilidade percebida de um produto e/ou serviço associada a um grupo social específico. As alternativas de compra ou de consumo passam a ter valor social a partir da associação positiva ou negativa que o consumidor faz com alguns aspectos socioeconômicos intrínsecos a um grupo social, em que a imagem e a reputação da marca para esse grupo refletem o seu respectivo valor social.

\section{MÉTODO DE PESQUISA}

Para a identificação da imagem de preço, utilizou-se o MCI que se baseia em distintos métodos já desenvolvidos e validados (De Toni, 2009; Schuler et al., 20I4). O MCI, dentre as diferentes etapas contempladas, propõe uma abordagem denominada configuração de conteúdo, buscando a identificação dos atributos salientes da imagem de um determinado objeto na mente dos respondentes; a atribuição de valores de ordem (VO) e valores de frequência (VF) aos atributos citados, visando à determinação das suas distâncias em relação ao termo empregado para estimular os respondentes a se manifestar sobre o objeto pesquisado (termo indutor); e a identificação da configuração das imagens, nesse caso, do preço de um produto a partir das suas dimensões.

Com base na adaptação dos procedimentos propostos pela literatura (Abric, ı998a, I998b; Moscovici, I978; Sá, ı996; De Toni, 2009; Schuler et al., 2010), foi implementado um método para a configuração de imagens de preço, com fins exploratórios.

Esse procedimento costuma ser feito a partir de uma questão geral, seguida de uma questão para cada dimensão da imagem de preço. No entanto, como a identificação dessas dimensões já fora testada em um estudo anterior (Schuler et al., 2010), optou-se por fazer apenas uma questão que buscasse, mesmo que de forma não tão profunda, identificar como se configura a imagem do preço de vestuário a partir do preço informado para os entrevistados. Para tanto, a questão norteadora foi: "Quando o(a) Sr.(a) pensa ou ouve falar no preço deste produto, que ideias ou palavras vêm à sua mente? Por favor, registre essas ideias ou palavras no espaço a seguir". Essa pergunta é uma adaptação da forma de entrevista do MCI, adotada no estudo de Schuler et al. (20I4), e que foi previamente testada. 
Antes de responder à questão apresentada, cada respondente foi convidado a imaginar uma "peça de vestuário ou um acessório", cujo preço aproximado de venda nas lojas era de $\mathrm{R} \$ 500,00$. A proposição do preço surgiu a partir de um estudo exploratório feito nas cinco principais lojas de confecções da mesma cidade onde foi realizada a pesquisa. Os resultados indicaram que o público jovem de classe média entre 20 a 30 anos costuma gastar, em média, de $R \$$ 300,00 a R \$ 600,00 quando compra vestuário. Desse modo, a resposta à questão apresentada levou em consideração esse particular tipo de produto e nível de preço.

Tal como propõe o MCI, quanto à análise dos resultados, o tratamento dos dados foi realizado a partir da análise de conteúdo das respostas geradas a partir da questão apresentada. Segundo Bardin (2002, p. 42),

[...] a análise de conteúdo consiste num conjunto de técnicas de análise das comunicações visando obter, por procedimentos sistemáticos e objetivos de descrição do conteúdo das mensagens, indicadores (quantitativos ou não) que permitam a inferência de conhecimentos relativos às condições de produção/recepção (variáveis inferidas) destas mensagens.

A análise de conteúdo implementada no trabalho obedeceu à seguinte ordem. Inicialmente, foram listadas todas as ideias mencionadas pelos respondentes, gerando os atributos pertinentes à imagem de preço de vestuário. Em seguida, os atributos mencionados foram categorizados a partir da análise de três experts, pesquisadores com experiência na categorização desses conteúdos, seguindo a técnica de juízes, proposta por Malhotra (200I), para dar maior validação ao conteúdo.

Assim, foi analisada a multidimensionalidade dos atributos da imagem do preço, dentro das áreas de valor percebido do produto e de percepção do sacrifício exigido para sua aquisição, nas dimensões: funcional, emocional, simbólica, de justiça, axiomática e social.

\subsection{AMOSTRA E COLETA DE DADOS}

A coleta dos dados foi realizada durante o mês de novembro de $20 \mathrm{o} 0$, em uma universidade da Serra Gaúcha, em que se utilizou o método de amostragem não probabilístico por conveniência. A abordagem aos respondentes foi realizada em sala de aula, e cada estudante recebeu uma folha convidando a imaginar uma peça de vestuário ou acessório cujo preço aproximado de venda nas lojas era de 
$\mathrm{R} \$ 500,00$. Em seguida, o participante deveria responder à questão-estímulo e mencionar tudo o que lhe viesse à mente quando pensa no preço do produto. $\mathrm{O}$ tempo médio de resposta foi de dez minutos.

Dos 337 respondentes, ou casos válidos da amostra, 54,6\% são do gênero masculino. Em relação à idade, $65 \%$ dos respondentes têm menos de 25 anos. A renda mensal individual de até R \$ I.000,00 correspondeu a 29,4\% da amostra; $52,8 \%$ ganham entre $\mathrm{R} \$ \mathrm{I} .00 \mathrm{I}, 00$ e $\mathrm{R} \$ 2.000,00$; e I7,8\%, mais de $\mathrm{R} \$ 2.000,00$.

\section{ANÁlise dA CONFIgURAÇÃo DOS ATRIBUTOS E DIMENSÕEs DAS IMAGENS DE PREÇO}

A partir de uma questão aberta em que o respondente foi convidado a escrever tudo o que lhe viesse à mente sobre o objeto de pesquisa - no caso desta pesquisa, imagem do preço de vestuário ou de um acessório -, realizou-se uma análise de conteúdo das respostas. Com base nas respostas dos 337 entrevistados, foram identificados 37 atributos. Essa fase do tratamento dos dados foi a mais delicada, pois exigiu habilidade para extrair a essência da ideia expressa pelos respondentes.

O MCI propõe que os atributos identificados passem por um primeiro tratamento, pelo qual são levantadas a sua frequência e ordem de evocação. Esse tratamento dos dados foi proposto inicialmente por Abric (I984) e Vergès (I992), e visa criar uma distinção entre os atributos mais próximos e os mais distantes do termo indutor. Os mais próximos serão considerados como pertencentes à imagem central, e os mais distantes serão localizados na periferia da imagem.

A Tabela I, portanto, apresenta, além dos atributos da imagem do preço de vestuário/acessório para a amostra, o VF, o VO e o valor total (VT) de cada atributo. O VF é o número de vezes em que o atributo foi citado pelos respondentes. Para atribuir um VO, o atributo citado em primeiro lugar recebe valor 5; em segundo lugar, recebe valor 4; em terceiro lugar, valor 3; em quarto lugar, valor 2; e, em quinto lugar, valor I. Após o quinto lugar, os atributos não mais recebem um valor $(\mathrm{VO}=\mathrm{o})$, apenas o VF. Por sua vez, o VT é um somatório simples do VO com o VF. Os atributos que se destacam por um alto VF e alto VO, então, terão um alto VT e serão considerados como candidatos a compor a imagem central do produto em estudo.

Como analisado na literatura, toda e qualquer representação é organizada em torno de um núcleo ou imagem central e que dá à representação um significado, 
ocupando uma posição privilegiada na mente dos pesquisados. Já os atributos que pertencem às periferias são mais flexíveis e sujeitos às mudanças, cuja função é permitir a adaptação à realidade (Abric, I984; Sá, I996). Dessa forma, a imagem central é mais comum, mais frequente e prontamente lembrada nas representações dos pesquisados, enquanto as imagens periféricas são elementos mais particularizados. Para gerar diferentes áreas de proximidade com o estímulo dado para evocar a imagem do produto junto aos participantes da pesquisa (termo indutor), aplicou-se a divisão por quartis (Microsoft Excel) ao conjunto de VTs encontrados. Sendo assim, foi possível identificar quatro grupos de atributos: a periferia da imagem, composta pelo primeiro quartil (VT = 6 a I9); a segunda periferia da imagem, formada pelo quartil que abriga os atributos com $\mathrm{VT}=2 \mathrm{I}$ a 33 ; a primeira periferia, representada pelo terceiro quartil $(\mathrm{VT}=34 \mathrm{a}$ 55); e a imagem central do produto, contemplando o conjunto de atributos com maior VT (VT $=64$ a 686) (Tabela I).

\section{TABELA I}

CONFIGURAÇÃO DA IMAGEM DE PREÇO

DE VESTUÁRIO OU ACESSÓRIO

\begin{tabular}{|c|c|c|c|c|c|c|c|}
\hline $\begin{array}{l}\text { NIVEIS DA } \\
\text { IMAGEM }\end{array}$ & & ATRIBUTOS IDENTIFICADOS & VF & vo & VT & $\% / V T$ & $\begin{array}{l}\text { DIMENSÕES } \\
\text { DA IMAGEM }\end{array}$ \\
\hline \multirow{10}{*}{$\begin{array}{c}\text { Imagem } \\
\text { central }\end{array}$} & 1 & Qualidade & 127 & 559 & 686 & 21,88 & Funcional \\
\hline & 2 & Caro & 114 & 525 & 639 & 20,38 & Justiça \\
\hline & 3 & Marca & 70 & 277 & 347 & 11,07 & Funcional \\
\hline & 4 & Custo versus benefício & 38 & 159 & 197 & 6,28 & Justiça \\
\hline & 5 & Status & 31 & 99 & 130 & 4,15 & Simbólica \\
\hline & 6 & Absurdo: exagero & 23 & 100 & 123 & 3,92 & Justiça \\
\hline & 7 & Diferenciação & 17 & 60 & 77 & 2,46 & Social \\
\hline & 8 & Durabilidade & 15 & 55 & 70 & 2,23 & Funcional \\
\hline & 9 & Não compraria/não gastaria & 15 & 52 & 67 & 2,14 & Axiomática \\
\hline & 10 & Exclusividade & 13 & 51 & 64 & 2,04 & Social \\
\hline
\end{tabular}

(continua) 
TABELA I (CONTINUAÇÃO)

CONFIGURAÇÃO DA IMAGEM DE PREÇO

DE VESTUUÁRIO OU ACESSÓRIO

\begin{tabular}{|c|c|c|c|c|c|c|c|}
\hline $\begin{array}{l}\text { NÍVEIS DA } \\
\text { IMAGEM }\end{array}$ & & ATRIBUTOS IDENTIFICADOS & VF & VO & VT & $\% / V T$ & $\begin{array}{l}\text { DIMENSÕES } \\
\text { DA IMAGEM }\end{array}$ \\
\hline \multirow{9}{*}{$\begin{array}{l}\text { Primeira } \\
\text { periferia }\end{array}$} & 11 & Moderno & 12 & 43 & 55 & 1,75 & Simbólica \\
\hline & 12 & Beleza: bonito & 12 & 42 & 54 & 1,72 & Simbólica \\
\hline & 13 & Risco & 11 & 41 & 52 & 1,66 & Justiça \\
\hline & 14 & Conforto & 13 & 32 & 45 & 1,43 & Funcional \\
\hline & 15 & Sem condições de adquirir & 9 & 34 & 43 & 1,37 & Axiomática \\
\hline & 16 & Acessível à classe alta & 8 & 29 & 37 & 1,18 & Social \\
\hline & 17 & Estilo & 8 & 26 & 34 & 1,08 & Simbólica \\
\hline & 18 & Luxo & 7 & 27 & 34 & 1,08 & Simbólica \\
\hline & 19 & Similar mais barato & 7 & 27 & 34 & 1,08 & Justiça \\
\hline \multirow{9}{*}{$\begin{array}{l}\text { Segunda } \\
\text { periferia }\end{array}$} & 20 & Moda & 8 & 25 & 33 & 1,05 & Simbólica \\
\hline & 21 & Utilidade & 6 & 26 & 32 & 1,02 & Funcional \\
\hline & 22 & Design & 7 & 20 & 27 & 0,86 & Funcional \\
\hline & 23 & Elegância & 6 & 21 & 27 & 0,86 & Simbólica \\
\hline & 24 & Necessidade & 6 & 20 & 26 & 0,83 & Axiomática \\
\hline & 25 & Satisfação & 6 & 25 & 31 & 0,99 & Emocional \\
\hline & 26 & Confiança: segurança & 4 & 18 & 22 & 0,70 & Axiomática \\
\hline & 27 & Desnecessário & 6 & 21 & 27 & 0,86 & Axiomática \\
\hline & 28 & Poder & 4 & 17 & 21 & 0,67 & Simbólica \\
\hline
\end{tabular}

(continua) 
TABELA I (CONCLUSÃO)

CONFIGURAÇÃO DA IMAGEM DE PREÇO

DE VESTUÁRIO OU ACESSÓRIO

\begin{tabular}{|c|c|c|c|c|c|c|c|}
\hline $\begin{array}{l}\text { NÍVEIS DA } \\
\text { IMAGEM }\end{array}$ & & ATRIBUTOS IDENTIFICADOS & VF & VO & VT & $\% / V T$ & $\begin{array}{l}\text { DIMENSÕES } \\
\text { DA IMAGEM }\end{array}$ \\
\hline \multirow{9}{*}{ Periferia } & 29 & Bom acabamento & 4 & 15 & 19 & 0,61 & Funcional \\
\hline & 30 & Irritado/ridículo & 3 & 15 & 18 & 0,57 & Emocional \\
\hline & 31 & Bem-estar & 4 & 10 & 14 & 0,45 & Emocional \\
\hline & 32 & Bom gosto & 3 & 10 & 13 & 0,41 & Emocional \\
\hline & 33 & Funcionalidade & 3 & 7 & 10 & 0,32 & Funcional \\
\hline & 34 & Superficial & 2 & 8 & 10 & 0,32 & Axiomática \\
\hline & 35 & Alto lucro & 1 & 5 & 6 & 0,19 & Justiça \\
\hline & 36 & Desconto & 1 & 5 & 6 & 0,19 & Justiça \\
\hline & \multirow[t]{2}{*}{37} & Qualidade duvidosa & 1 & 5 & 6 & 0,19 & Funcional \\
\hline & & Total & 627 & & 3.136 & 100 & \\
\hline
\end{tabular}

Fonte: Elaborada pelos autores.

Os atributos da imagem central, ou seja, aqueles que dão significado ao conceito de imagem de preço de uma peça de vestuário ou acessório, cujo preço aproximado é de $\mathrm{R} \$ 500,00$, estão relacionados a um produto de: "qualidade", com preço "alto/injusto", "marca [reconhecida]", com boa relação "custo versus benefício", que provê "status", de "valor agregado", com preço, às vezes, "absurdo", ligado à "diferenciação", de boa "durabilidade", que talvez "não compraria/não gastaria [tal valor]", relacionado a "exclusividade" e "moderno", além de transmitir "beleza". Dessa forma, pode-se pressupor que, para os entrevistados, a imagem do preço de um vestuário com o valor aproximado de $\mathrm{R} \$ 500,00$ está fortemente associada a um produto "caro", porém, com uma boa qualidade e com uma marca famosa (reconhecida), o que, para muitos, é justo, apresentando uma boa relação custo versus benefício, ou seja, seria justo pagar este preço, pois há um valor agregado.

No tratamento das dimensões da imagem do preço de vestuário ou acessório, identificou-se que todas as dimensões sugeridas por meio da revisão da literatura estavam presentes nas representações dos entrevistados, porém, com pesos diferentes. A Tabela 2 apresenta tal resultado a partir da análise de conteúdo das dimensões e do percentual de cada uma dessas dimensões sobre a frequência de citação. 
TABELA 2

DIMENSÖES DA IMAGEM DE PREÇO

DE VESTUÁRIO OU ACESSÓRIO

\begin{tabular}{|c|c|c|c|c|c|}
\hline DIMENSÕES DA IMAGEM & ÁREA & \multicolumn{2}{|c|}{ TOTAL } & \multicolumn{2}{|c|}{$\%$} \\
\hline \multirow{2}{*}{ Funcional } & $S$ & 1 & \multirow{2}{*}{248} & 0,16 & \multirow{2}{*}{40} \\
\hline & B & 247 & & 39,39 & \\
\hline \multirow{2}{*}{ Justiça } & $S$ & 157 & \multirow{2}{*}{195} & 25,04 & \multirow{2}{*}{31} \\
\hline & B & 38 & & 6,06 & \\
\hline \multirow{2}{*}{ Simbólica } & S & 0 & \multirow{2}{*}{88} & 0,00 & \multirow{2}{*}{14} \\
\hline & B & 88 & & 14,04 & \\
\hline \multirow{2}{*}{ Axiomática } & S & 32 & \multirow{2}{*}{42} & 5,10 & \multirow{2}{*}{7} \\
\hline & B & 10 & & 1,59 & \\
\hline \multirow{2}{*}{ Social } & $S$ & 8 & \multirow{2}{*}{38} & 1,28 & \multirow{2}{*}{6} \\
\hline & B & 30 & & 4,78 & \\
\hline \multirow{2}{*}{ Emocional } & S & 3 & \multirow{2}{*}{16} & 0,48 & \multirow{2}{*}{2} \\
\hline & B & 13 & & 2,07 & \\
\hline \multirow{2}{*}{ Total } & S & 201 & \multirow{2}{*}{627} & 32,06 & \multirow{2}{*}{100,00} \\
\hline & B & 426 & & 67,94 & \\
\hline
\end{tabular}

S: sacrifício e B: benefício.

Fonte: Elaborada pelos autores.

Quando os respondentes foram solicitados a dar sua ideia ao pensarem no preço do vestuário ou acessório cujo preço de venda nas lojas, em geral, fosse em torno de $\mathrm{R} \$ 500,00$, foram coletadas 627 citações. A dimensão com maior frequência é a dimensão funcional, com 248 manifestações (40\% das citações), das quais apenas uma citação está relacionada a um sacrifício; as outras 247 citações estão ligadas a algum tipo de benefício. Entre os benefícios que se destacam na dimensão funcional, estão os relacionados às manifestações concernentes à qualidade do produto, e, quanto ao sacrifício percebido, este indica que o produto possui "qualidade duvidosa". 
A segunda dimensão com maior frequência foi a dimensão de justiça, com I95 manifestações (31\% das citações). Levando em conta que a percepção de um preço injusto está associada a várias emoções negativas (Xia et al., 2004), considera-se que o atributo "caro" tem uma forte relação com a percepção de um "preço injusto", o que pode despertar algumas emoções negativas no consumidor.

A terceira dimensão com maior frequência foi a dimensão simbólica, com 88 citações (I4\%), as quais estão, na sua maioria, relacionadas ao que o preço representa. Observa-se que destas 3I citações estão ligadas ao status, ou seja, para os entrevistados há uma forte associação do preço informado com o que o produto pode proporcionar em termos de status. Outros atributos, tais como, "moderno", "beleza/bonito", "luxo", "elegância" e "moda”, também são manifestações que expressam benefícios provenientes da compra de um produto do nível de preço sugerido (em torno de $\mathrm{R} \$ 500,00$ ).

A quarta dimensão mais citada foi a dimensão axiomática, que gerou 42 citações (7\%), com destaque para os sacrifícios percebidos (32 citações). Entre os sacrifícios, destaca-se que o produto no nível preço sugerido é um "desperdício" e que seria "desnecessário" gastar todo esse valor na compra de uma peça de vestuário ou um acessório. Quanto aos benefícios da dimensão axiomática, há várias expressões que afirmam que o produto no nível de sugerido repercute em "confiança”, provavelmente por estar associado a uma empresa ou marca reconhecida.

Na dimensão social, houve 38 manifestações (6\%), e, nessa dimensão, há uma sobrevalorização dos benefícios (30 citações) sobre o sacrifício (8 citações). Entre os sacrifícios, destaca-se a percepção de que "são poucos os consumidores que conseguem comprar" o vestuário ou o acessório no nível de preço sugerido, restringindo-o somente à classe alta. No entanto, houve 30 manifestações de cunho social relativas ao preço, indicando que ele pode transmitir a ideia de "diferenciação" e "exclusividade".

Por fim, a dimensão emocional foi a que menos gerou manifestações (I6 ou $2 \%$ ), sendo que houve apenas 3 manifestações de "irritação" com o nível de preço informado, sugerindo a incidência de uma emoção negativa. As I3 citações estão relacionadas aos sentimentos de "satisfação" e de "bem estar" ao comprar ou usar um produto com o preço informado, podendo ser considerado como manifestações ligadas a emoções positivas.

Assim sendo, pode-se dizer que a imagem central de uma peça de vestuário ou um acessório no valor de cerca de $\mathrm{R} \$ 500,00$ está fortemente relacionada aos benefícios funcionais (qualidade e marca reconhecida) e ao benefício de justiça (boa relação custo versus benefício), além de um sacrifício emocional e de justiça (caro, absurdo). De modo que, apesar de ser considerado pelos pesquisados uma peça de vestuário ou um acessório caro, os benefícios (qualidade e marca reconhecida) compensariam o sacrifício (caro). 


\subsection{GRÁFICO DE CONFIGURAÇÃO DA IMAGEM E AÇÕES ESTRATÉGICAS PARA A GESTÃO DA IMAGEM DE PREÇO DE PRODUTO}

Com o objetivo de apresentar uma forma de visualização da configuração da imagem de preço de produto, é possível construir diferentes mapas de imagem (De Toni, 2009; Schuler et al., 20I4). Um deles pode ser a partir das imagens centrais e periféricas, como foram apresentadas na Tabela I. Outra forma de representação dos resultados, e que é proposta neste trabalho, é a partir da representatividade de cada dimensão sobre a imagem de preço de produto. Nesse sentido, foi utilizada a frequência total de cada atributo como valor para dividir o mapa da configuração da imagem em partes proporcionais, na base de Io०\%, para identificar a proporção de cada dimensão sobre o total a ser analisado, conforme visto na Tabela 2.

Portanto, por meio do Gráfico I, é possível visualizar diferentes e importantes informações em relação à imagem de preço. A primeira informação mostra a disposição dos atributos de acordo com a imagem central. Para isso, observa-se que os atributos de I a Io, conforme apresentados na Tabela I, pertencem à imagem central do preço do vestuário ou acessório, enquanto os atributos II a I9 pertencem à primeira periferia e assim por diante. A segunda informação mostra a categorização de cada atributo nas seis diferentes dimensões da imagem, mostrando também a representatividade de cada dimensão sobre a percepção dos partícipes da pesquisa.

\section{GRÁFICO I}

\section{GRÁFICO DE CONFIGURAÇÃO DA IMAGEM} DO PREÇO DO VESTUÁRIO OU ACESSÓRIO

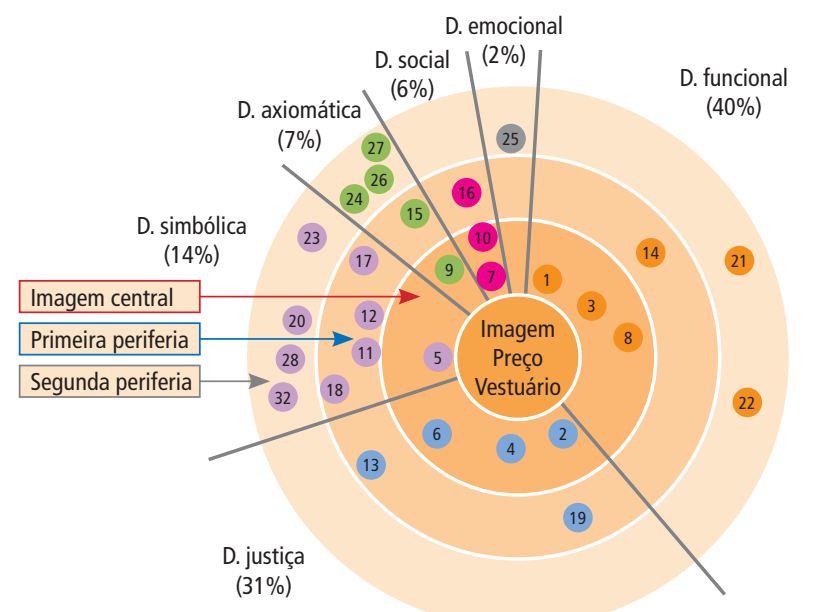

Fonte: Elaborado pelos autores com base em De Toni (2009) e Schuler et al. (20I4). 
O Quadro I apresenta os resultados da configuração da imagem do preço do vestuário ou acessório, bem como as ações estratégicas que poderiam ser desenvolvidas para trabalhar sua imagem junto a esse público. A partir do Gráfico I e das tabelas I e 2, é possível analisar e propor ações estratégicas que visem fortalecer a imagem do produto investigado.

\section{QUADRO I}

\section{AÇÕES ESTRATÉGICAS A PARTIR DA POSIÇÃO RELATIVA \\ DE CADA ATRIBUTO E DE CADA DIMENSÃO DA IMAGEM \\ DE PREÇO DO VESTUÁRIO OU ACESSÓRIO}

\begin{tabular}{|c|c|c|c|c|c|}
\hline DIMENSÕES & ATRIBUTOS & $\begin{array}{c}\text { POSIÇÃO } \\
\text { NA } \\
\text { IMAGEM }\end{array}$ & $\begin{array}{c}\text { SACRIFÍCIO } \\
\text { OU } \\
\text { BENEFÍCIO }\end{array}$ & RECOMENDAÇÕES & AÇÕES ESTRATÉGICAS ${ }^{1}$ \\
\hline \multirow[t]{2}{*}{$\begin{array}{c}\text { Funcional } \\
(40 \%)\end{array}$} & Durabilidade & \multirow[t]{2}{*}{ Central } & \multirow[t]{2}{*}{ Benefício } & $\begin{array}{l}\text { Manter a posição } \\
\text { do atributo e } \\
\text { aumentar a } \\
\text { percepção da } \\
\text { sua importância. }\end{array}$ & $\begin{array}{l}\text { Manter e aumentar cada vez mais a } \\
\text { qualidade desse produto é um fator } \\
\text { fundamental para a imagem positiva } \\
\text { do vestuário. Como a qualidade é uma } \\
\text { dimensão funcional que tem uma } \\
\text { forte influência na Imagem de } \\
\text { preço como valor e está fortemente } \\
\text { relacionada com a percepção de } \\
\text { justiça, com a dimensão simbólica } \\
\text { e emocional positiva, é importante } \\
\text { salientar os benefícios que tal produto } \\
\text { pode apresentar e que seu preço é } \\
\text { justo em função de ter qualidade } \\
\text { e durabilidade superiores. }\end{array}$ \\
\hline & Marca & & & $\begin{array}{l}\text { Manter a posição } \\
\text { do atributo e } \\
\text { aumentar a } \\
\text { percepção de } \\
\text { sua importância. }\end{array}$ & $\begin{array}{l}\text { A marca e a qualidade são benefícios } \\
\text { percebidos que formam a dimensão } \\
\text { funcional e têm uma forte influência } \\
\text { nas intenções de compra. Portanto, } \\
\text { uma marca forte transmite } \\
\text { confiabilidade, o que justifica o } \\
\text { "caro". Expressões como "é cara, } \\
\text { mas compensa o preço" retratam } \\
\text { tais pressupostos. }\end{array}$ \\
\hline
\end{tabular}

(continua) 
QUADRO I (CONTINUAÇÃo)
AÇÕES ESTRATÉGICAS A PARTIR DA POSIÇÃO RELATIVA
DE CADA ATRIBUTO E DE CADA DIMENSÃO DA IMAGEM
DE PREÇO DO VESTUÁRIO OU ACESSÓRIO

\begin{tabular}{|c|c|c|c|c|c|}
\hline DIMENSÕES & ATRIBUTOS & $\begin{array}{c}\text { POSIÇÃOO } \\
\text { NA } \\
\text { IMAGEM }\end{array}$ & $\begin{array}{l}\text { SACRIFÍCIO } \\
\text { OU } \\
\text { BENEFÍCIO }\end{array}$ & RECOMENDAÇÕES & AÇÕES ESTRATÉGICAS ${ }^{1}$ \\
\hline
\end{tabular}

Justiça

(31\%)

$\begin{array}{ccl}\begin{array}{c}\text { Custo versus } \\ \text { benefício }\end{array} \quad \text { Central } & \begin{array}{c}\text { Sacrifício } \\ \text { versus } \\ \text { benefício }\end{array} & \begin{array}{l}\text { Manter a posição } \\ \text { do atributo e da } \\ \text { dimeño. }\end{array}\end{array}$

Caro

Afastar os

atributos da

imagem central.
Preço

Absurdo
A percepção de que o preço do vestuário informado "tem um custo alto, mas tem um benefício" é positiva, uma vez que exorta um bom valor agregado ao produto. Apesar de ser considerado caro, leva-se em conta o valor informado de $R \$ 500,00$ para vestuário. Como recomendação estratégica na formação de um preço para o vestuário, é importante levar em conta os benefícios que ele proporcionará, de forma que isso poderá automaticamente isolar os efeitos negativos do sacrifício (caro) da imagem do preço do vestuário. Além disso, as comunicações de percepção de valor no produto poderão ser direcionadas para determinados públicos-alvo (por exemplo, pessoas altamente envolvidas com esse tipo de produto), cujo benefício percebido num vestuário nesse preço é superior ao sacrifício.

Esses atributos representam um sacrifício e têm um impacto negativo na imagem de preço como valor. Além disso, também apresentam uma forte correlação com a percepção de justiça. Para os entrevistados, o preço informado de cerca de $\mathrm{R} \$ 500,00$ para o vestuário ou acessório é considerado caro. A recomendação estratégica é comunicar valor a partir das especificações de qualidade, marca, status etc. que o vestuário pode proporcionar ao consumidor, neutralizando, assim, os efeitos negativos dessas variáveis.

(continua) 
QUADRO I (CONCLUSÃO)
AÇÕES ESTRATÉGICAS A PARTIR DA POSIÇÃO RELATIVA
DE CADA ATRIBUTO E DE CADA DIMENSÃO DA IMAGEM
DE PREÇO DO VESTUÁRIO OU ACESSÓRIO

\begin{tabular}{|c|c|c|c|c|c|}
\hline DIMENSÕES & ATRIBUTOS & $\begin{array}{c}\text { POSIÇÃO } \\
\text { NA } \\
\text { IMAGEM }\end{array}$ & $\begin{array}{c}\text { SACRIFÍCIO } \\
\text { OU } \\
\text { BENEFÍCIO }\end{array}$ & RECOMENDAÇÕES & AÇÕES ESTRATÉGICAS ${ }^{1}$ \\
\hline $\begin{array}{l}\text { Social } \\
(6 \%)\end{array}$ & Diferenciação & Central & Benefício & $\begin{array}{l}\text { Manter a posição } \\
\text { dos atributos. }\end{array}$ & $\begin{array}{l}\text { Esses dois atributos de natureza } \\
\text { social estão também associados } \\
\text { com atributos de natureza simbólica. } \\
\text { Trata-se de atributos que estão na } \\
\text { imagem central e são altamente } \\
\text { percebidos como benefício que o } \\
\text { vestuário no preço informado poderá } \\
\text { proporcionar. Nesse sentido, como } \\
\text { ação estratégica de comunicação, é } \\
\text { importante salientar que o vestuário } \\
\text { no preço de } \mathrm{R} \$ 500,00 \text { tem seu valor, } \\
\text { uma vez que pode proporcionar uma } \\
\text { diferenciação e exclusividade. }\end{array}$ \\
\hline $\begin{array}{l}\text { Simbólica } \\
(14 \%)\end{array}$ & Status & Central & Benefício & $\begin{array}{l}\text { Manter a posição } \\
\text { dos atributos. }\end{array}$ & $\begin{array}{l}\text { Uma comunicação que enfatize o } \\
\text { quanto o produto contribui para } \\
\text { aumentar o status e o poder é uma } \\
\text { estratégia importante, uma vez que } \\
\text { a dimensão simbólica está fortemente } \\
\text { relacionada com a dimensão social. }\end{array}$ \\
\hline $\begin{array}{l}\text { Emocional } \\
\qquad(2 \%)\end{array}$ & Satisfação & Periferia & Benefício & $\begin{array}{l}\text { Procurar } \\
\text { aproximar da } \\
\text { imagem central. }\end{array}$ & $\begin{array}{l}\text { As emoções têm um forte impacto } \\
\text { na imagem. Nesse sentido, quando se } \\
\text { direcionam estratégias de formação } \\
\text { de preço, é importante estar atento } \\
\text { aos tipos de emoção que um preço } \\
\text { mal posicionado pode causar na } \\
\text { mente do consumidor. Um preço que } \\
\text { cause satisfação e bem-estar está } \\
\text { fortemente relacionado à percepção } \\
\text { de justiça. O consumidor poderá } \\
\text { pagar um preço alto por um produto } \\
\text { e mesmo assim ficar satisfeito, } \\
\text { contanto que o produto ou marca } \\
\text { seja valorizado por ele. }\end{array}$ \\
\hline
\end{tabular}

${ }^{\mathrm{r}}$ As ações estratégicas propostas são apenas sugestões para ilustrar a aplicabilidade desta pesquisa. Tais ações necessitam ser adaptadas a uma análise mais profunda do setor, segmento ou nicho de mercado específico em que os produtos são ofertados e estão posicionados, bem como dos recursos e das capacidades de cada empresa.

Fonte: Elaborado pelos autores. 
Outra forma de administrar de forma estratégica a imagem do preço do produto é compreender mais claramente a segmentação dentro do seu público consumidor. Para consumidores com alto envolvimento com o produto ou pessoas que leem constantemente sobre o produto específico, uma comunicação que saliente os aspectos funcionais e de justiça é fundamental. Dessa forma, uma comunicação mais efetiva deverá priorizar detalhes do produto com informações como as características técnicas do produto, o processo utilizado etc. $\mathrm{Na}$ maior parte das vezes, esse público adquire esse tipo de produto com preço maior, pois a percepção de benefícios (por exemplo, qualidade e marca reconhecidas) geralmente é superada pela percepção dos sacrifícios (por exemplo, preço pago e possível arrependimento pela compra).

Por sua vez, os consumidores com baixo envolvimento com o produto normalmente compram produtos sem se concentrar em detalhes, baseando-se muito mais em dicas heurísticas ou evidências extrínsecas fornecidas por amigos ou conhecidos que já utilizaram, compraram ou consumiram tais produtos ou marcas indicadas. Uma comunicação com elementos simbólicos e emocionais, realizada por formadores de opinião, talvez seja mais interessante e de efeito mais profundo e consistente para esse tipo específico de consumidor (Beaujanot, 2004). Essa compreensão mais sutil das diferenças na imagem relativa ao preço de produtos pode ser analisada a partir da geração de estratégias específicas para cada segmento-alvo e também do tipo de produto a ser analisado.

\section{CONSIDERAÇÕES FINAIS}

A intenção de compra do consumidor pode ser orientada a partir de diferentes direcionamentos. No entanto, percebe-se que dois temas têm um papel fundamental na influência sobre as compras: a imagem e o preço. A imagem como um construto complexo constitui um dos materiais intelectuais mais importantes do homem, pois é capaz de influenciar e direcionar o comportamento das pessoas. O preço é o segundo elemento mais impactante na estratégia de marketing das empresas depois do produto (Samiee, I987).

Dentre as contribuições desta pesquisa, a primeira é referente ao tema de imagem de preço de produto. Observou-se, ao longo da revisão da literatura, que o estudo da imagem de preço é um tema pouco abordado. Zielke (2006, 20IO, 20II), um dos poucos pesquisadores que abordam diretamente esse tema, trabalha com a questão de imagem de preço de estabelecimentos comerciais. Portanto, não se identificaram pesquisas que tratam diretamente de imagem de preço de produto. Por serem pouco abordados, buscou-se compreender como esses dois temas interconectados podem explicar o comportamento de compra 
ou de consumo, uma vez que têm uma forte influência nas decisões de compra e, consequentemente, no volume de vendas das organizações (Monroe, I990; Nagle \& Holden, 2003).

Por meio de diferentes estudos anteriores realizados com as imagens (De Toni, 2009), identificou-se que a imagem é um construto latente e multidimensional, além de ser formada de diferentes dimensões, de acordo com o objeto a ser pesquisado. No caso de imagem de preço de produto, identifica-se que ela está associada com seis dimensões: funcional, emocional, simbólica, de justiça, axiomática e social. Aliás, muitas dessas dimensões da imagem do preço não são independentes, estando inter-relacionadas entre si (Zielke, 2010).

A segunda contribuição foi entender o processo de configuração da imagem. A partir de uma adaptação do MCI, identificaram-se a imagem central do conceito e a organização dela no que tange às dimensões de preço de produto. Os resultados indicam que, para os respondentes, a imagem de preço de vestuário no valor de $\mathrm{R} \$ 500,00$ está associada a um produto caro, porém com uma boa qualidade e com uma marca famosa, o que para muitos é justo (custo versus benefício) pagar por esse preço, pois há um valor agregado. As três dimensões mais salientes e frequentes na mente dos respondentes são: a dimensão funcional (40\%), de justiça (31\%) e simbólica (I4\%). Tais achados de pesquisa são importantes para melhor entender e posicionar o preço de um produto no mercado. $\mathrm{O}$ fato, por exemplo, de apresentar um produto com preço elevado no mercado, mesmo as pessoas considerando um preço "alto", pode ser justificado por apresentar uma "marca reconhecida" (uma grife) ou "qualidade" superior, cujo valor percebido seja favorável. Nesse caso, os benefícios (qualidade e marca) superam os sacrifícios (o fato de ser caro e de difícil acesso), além de influenciarem positivamente a intenção de compra.

A partir desses resultados, é possível melhor entender que a imagem de preço é multidimensional, composta de vários atributos e dimensões fortemente relacionados entre si, formando uma rede de significados que influenciam as decisões de consumo. Com base nisso, uma terceira contribuição desta pesquisa é a proposição de uma figura-resumo e de um quadro orientador das ações estratégicas que uma organização pode fazer para trabalhar a imagem seja de preço, de produto, marca ou organização com o público-alvo. Observa-se que, em qualquer ação estratégica de comunicação, seja para manutenção, aproximação ou afastamento dos atributos da imagem central do produto, deve ser levada em conta não apenas a associação entre os atributos, mas também a percepção de valor (relação benefício versus sacrifício), a qual o preço de um produto pode sinalizar. No caso de vestuário e acessórios, muitas pessoas estão dispostas a pagar mais por um produto cuja marca ou qualidade são percebidos como um benefício maior que o sacrifício. 
Dentre as limitações desta pesquisa, é possível indicar algumas. A primeira está relacionada ao conceito de que o preço dos produtos per se não é inteiramente responsável pelas intenções ou decisões de compra dos consumidores. Como a própria teoria de marketing destaca, há outros fatores que são também importantes na explicação da intenção ou decisão de compra, não estudados aqui por transcenderem os objetivos do estudo, tais como estado da demanda, promoção de vendas, fatores situacionais de compra, entre outros aspectos (Krishna, 20II). Essas e outras variáveis podem ser levadas em conta para futuros estudos que queiram ampliar essa temática e agregar ao estudo proposto outras dimensões da imagem de preço que possam auxiliar no melhor entendimento acerca da imagem de preço dos produtos.

Uma segunda limitação se refere ao fato de a pesquisa empírica ter sido operacionalizada em uma situação hipotética de compra generalista, em que cada respondente foi convidado a imaginar uma peça de vestuário ou um acessório cujo preço aproximado de venda nas lojas era de $\mathrm{R} \$ 500,00$. A manipulação proposta é demasiada genérica para possibilitar a formação real do valor percebido do preço de um produto dentro da categoria proposta. Futuras pesquisas com cenários mais específicos, focando um produto particular e um preço de mercado ou até mesmo um experimento com diferentes preços para um mesmo produto, poderiam dar novos elementos para suportar as dimensões propostas.

Uma terceira limitação diz respeito à amostra por conveniência e composta por estudantes universitários. Dentre os estudantes pesquisados, $82,2 \%$ ganham menos que $\mathrm{R} \$ 2.000,00$, assim uma peça de vestuário no valor de $\mathrm{R} \$ 500,00$ pode representar mais que $30 \%$ de sua renda mensal. Tal fato pode ser percebido nas imagens centrais de suas manifestações como "caro", "absurdo, exagero". Portanto, para esse público, o preço proposto pode ser caracterizado como desproporcional à sua renda e, até certo ponto, parecer "injusto" ou "descabido". Dessa forma, uma nova alternativa de pesquisa com esse público é identificar a imagem a partir de diferentes níveis de preço. Todavia, pesquisas com uma amostra probabilística realizada com diferentes públicos poderiam agregar uma maior validade externa para a compreensão da imagem de preço de vestuário.

Como sugestão de direcionamento para futuras pesquisas, emerge a construção de uma escala para a mensuração da imagem de preço de produtos. Tal escala poderia ser um elemento importante para compreender como o consumidor configura suas imagens de preço de produtos e, com isso, melhor direcionar as estratégias de comunicação e apreçamento de produtos por parte das empresas.

Como implicações gerenciais, destaca-se que esforços de pesquisa devem ser direcionados para identificar como o consumidor percebe as informações de preço e como estas influenciam suas escolhas (Boom, 20II). A formação de 
qualquer estratégia de apreçamento pode começar com uma análise das imagens de preço que os consumidores têm e das diferentes formas de valor percebidas pelo indivíduo. Identificar e mensurar as dimensões que compõem a imagem de preço de um produto ou serviço auxilia na definição de estratégias de preço, principalmente se focadas na satisfação e na retenção ou na lealdade do consumidor dentro de uma perspectiva de customer lifetime value (valor do cliente) como forma de atingir uma maior lucratividade e rentabilidade para as empresas (Kamakura, Mittal, De Rosa, \& Mazzon, 2002).

Dentre as várias competências da organização, a gestão de preços assume um papel importante nas decisões estratégicas, na geração de receitas, na lucratividade e na rentabilidade das empresas (Vorhies \& Morgan, 2005). Empresas proativas na formação e definição de preços devem aprender como os clientes ou consumidores os percebem, quais imagens formaram os preços dos produtos que comercializam e como essa imagem influencia a percepção de valor e a intenção e decisão de compra ou de consumo das pessoas.

\section{MULTIDIMENSIONALITY OF PRODUCT PRICE IMAGE: A STUDY OF THE IMAGE PRICE OF APPAREL}

\section{ABSTRACT}

Understanding how price images are formed by several publics, is an important element for targeting strategies of product placement in the market, as well as the communication compound to support more accurately the performance of product price. This research aimed, firstly, to identify, from a literature review, dimensions that can better explain how product price image can be formed and, secondly, to examine how these dimensions are configured as the mental image of a target population. Results suggest that product price image, construed as a multidimensional latent variable, can configured within six dimensions: functional, emotional, symbolic, of justice, axiomatic and social. These attributes, associated with the perceived value, depict their own benefit or the sacrifice related to the analyzed dimension. From the image configuration method (ICM), it was made possible to study how these dimensions are configured in a sample of 337 undergraduate students from the price of a "apparel or furnishings", whose approximate sale price in stores were around R $\$ 500,00$. Findings show 627 quotes from respondents, with $68 \%$ of them being related to perceived benefits. Furthermore, the most salient dimensions were the functional dimension (related to perceived quality), of justice (verified from cost versus benefit) and 
the symbolic (identified from status and luxury). For a better viewing of results, a graph and a table illustrate how the product price imaget can be configured to assist in better targeting of communication strategies and product pricing.

\section{KEYWORDS}

Product price image. Perceived value. Image configuration. Image multidimensionality. Image configuration method.

\section{LA MULTIDIMENSIONALIDAD DE LA IMAGEN DEL PRECIO DEL PRODUCTO: UN ESTUDIO CON LA IMAGEN DEL PRECIO DE VESTUARIO}

\section{RESUMEN}

La comprensión de las imágenes que los diversos públicos forman acerca de los precios es un elemento importante para la orientación de estrategias para el posicionamiento de productos en el mercado, así como del compuesto de comunicación para que haya mejor rendimiento y actuación del precio de los productos. Esta investigación tuvo como objetivo, en primer lugar, utilizando la revisión de la literatura, identificar las dimensiones que mejor explican cómo se puede formar la imagen del precio de los productos y, en segundo lugar, verificar cómo estas dimensiones se configuran en la imagen mental de una determinada población. Los resultados sugieren que la imagen del precio de los productos, entendida como una variable latente y multidimensional, se puede establecer a partir de seis dimensiones: funcional, emocional, simbólica, de la justicia, axiomática y social; estas dimensiones están asociados con el valor percibido, que retrata el beneficio o el sacrificio de cada atributo relacionado a la dimensión analizada. Desde el método de configuración de imagen (MCI), fue posible estudiar cómo estas dimensiones se configuran en una muestra de 337 estudiantes de graduación, a partir del precio de una "pieza de vestuario o un accesorio", cuyo precio de venta en tiendas aproximado fuese de $\mathrm{R} \$ 500,00$. Los resultados muestran 627 citaciones de los que respondieron, donde $68 \%$ de ellas están relacionadas con los beneficios percibidos. Además, las dimensiones más destacadas fueron: la dimensión funcional (relacionada con la calidad percibida), la de justicia (verificada a partir del costo-beneficio) y la simbólica (identificada a partir del status y del lujo). Estos resultados están dispuestos en un gráfico y un 
panorama explicativo, lo que permite una mejor comprensión de cómo se puede configurar la imagen del precio del producto, ayudando a una mejor orientación de las estrategias de comunicación e información de precios de los productos.

\section{pAlabRAS CLAVE}

Imagen del precio. Valor percibido. Configuración de imágenes. Multidimensionalidad de la imagen. Método de configuración de imagen.

\section{REFERÊNCIAS}

Aaker, J., Drolet, A., \& Griffin, D. (20II). Recalling mixed emotions. [Working Paper]. Haas School of Business.

Abric, J. C. (1993). Central system, peripheral system: their functions and roles in the dynamics of social representations. Papers on Social Representations, 2, 75-78. Recuperado em 1o setembro, 2003, de http://www.psr.jku.at/psrindex.htm.

Abric, J. C. (I998a). L’approche struturale des représentations sociales: developments récents. Anais da Conferência Internacional sobre Representações Sociais. Cidade do México, México, 4.

Abric, J. C. (I998b). A abordagem estrutural das representações sociais. In A. S. P. Moreira \& D. C. Oliveira (Orgs.). Estudos interdisciplinares em representações sociais. Goiânia: AB Editora.

Alves Mazzotti. (2002). A. J. A Abordagem estrutural das representações sociais. Psicologia da Educação, (I4/15), I7-38.

Avlonitis, G., \& Indounas, K. A. (2006). Pricing practices of service organizations. Journal of Service Marketing, 20(5), 346-356.

Avlonitis, G., \& Indounas, K. A. (2007). An empirical examination of the pricing policies and their antecedents in the services sector. European Journal of Marketing, 41(7-8), 740-764.

Avlonitis, G., Indounas, K. A., \& Gounaris, (2005). S. P. Pricing objectives over the service life cycle: some empirical evidence. European Journal of Marketing, 39(5-6), 696-7I4.

Bagozzi, R. P., \& Dholakia, U. (I999). Goal setting and goal striving in consumer behavior. Journal of Marketing, 63(4), I9-32.

Bardin, L. (2002). Análise de conteúdo. Lisboa: Edições 70.

Bearden, W., Netemeyer, R., \& Teel, J. (1989). Measurement of consumer susceptibility to interpersonal influence. Journal of Consumer Research, 15(4), 473-48I.

Bolton, L. E., Warlop, L., \& Alba, J. W. (2003). Consumer perceptions of price (un)fairness. Journal of Consumer Research, 29(4), 474-49I.

Boom, W. H. (20II). Price intransparency, consumer decision making and european consumer law. Journal Consumer Policy, 34(3), 359-376.

Campbell, M. C. (I999). Perceptions of price unfairness: antecedents and consequences. Journal of Marketing Research, 36(2), I87-199.

Chernev, A. (2006). Articulation compatibility in eliciting price bids. Journal of Consumer Research, 33(3), 329-34I. 
Cohen, J. B., Pham, M. T., \& Andrade, E. B. (2008). The nature and role of affect in consumer behavior. In C. Haugtvedt, F. Karde \& P. Herr (Eds.). Handbook of consumer psychology. Mahwah: Erlbaum.

Costa, F. J. (2007). A influência do valor percebido pelo cliente sobre os comportamentos de reclamação e boca a boca: uma investigação em cursos de pós-graduação lato sensu. Tese de doutorado, Fundação Getulio Vargas, São Paulo, SP, Brasil.

De Toni, D. (2009). Administração da imagem de organizações, marcas e produtos. In M. M. K. Kunsch (Org.). Comunicação organizacional: histórico, fundamentos e processos (Vol. I). São Paulo: Saraiva. De Toni, D., \& Mazzon, J. A. (20I3). Imagem de preço de produto: proposição de um modelo conceitual. Revista de Administração da USP, 48(3), 454-468.

Dichter, E. (I985). What's in an image. Journal of Consumer Marketing, 2(I), 75-8I.

Dobni, D., \& Zinkhan, G. M. (I990). Search of grand image: a foundation analysis. Advances in Consumer Research, 17(I), IIO-II9.

Fernandes, D. H., \& Slongo, L. (2007). Antecedentes e consequências da injustiça no preço. Anais do Encontro da Associação Nacional de Pós-Graduação e Pesquisa em Administração, Rio de Janeiro, RJ, Brasil, 3I.

Galhanone, R. F. (2008). Atitudes, emoções e comportamento de compra: um estudo com consumidores de produtos de luxo ou sofisticados. Dissertação de mestrado, Universidade de São Paulo, São Paulo, SP, Brasil.

Goleman, D. (2007). Inteligência emocional: a teoria revolucionária que redefine o que é ser inteligente. Rio de Janeiro: Objetiva.

Guiltinan, J. P. (2000). Managing quality cues for product-line pricing. Journal of Product \& Brand Management, 9(3), 50-163.

Haws, K. L., \& Bearden, W. (2006). Dynamic pricing and consumer fairness perceptions. Journal of Consumer Research, 33(3), 304-3II.

Huangfu, G., \& Zhu, L. (2OI2). Do consumers' perceptions of price fairness differ according to type of firm ownership? Social Behavior and Personality, 40(4), 693-698.

Kahle, L., \& Kennedy, P. (I988). Using the list of values: LOV to understand consumer. The Journal of Services Marketing, 2(4), 49-56.

Kamakura, W. A., Mittal, V., De Rosa, F., \& Mazzon, J. A. (2002). Assessing the service-profit chain. Marketing Science, 21(3), 294-3I7.

Kim, J., Natter, M., \& Spann, M. (2009). Pay what you want: a new participative pricing mechanism. Journal of Marketing, 73(I), 44-58.

Krishna, C. V. (20II). Determinants of consumer buying behaviour: an empirical study of private label brands in apparel retail. Journal of Management, 8(2), 43-56.

Kukar-Kinney, M., Xia, L., \& Monroe, K. B. (2007). Consumers' perceptions of the fairness of price-matching refund policies. Journal of Retailing, 83(3), 325-337.

Lancioni, R. (1988). The importance of price in international business development. Asia Pacific International Journal of Business Logistics, 1(2), 45-50.

Laros, F. J. M., \& Steenkamp, J. E. M. (2003). Emotions in consumer behavior: a hierarchical approach. Journal of Business Research, 58(10), I437-I445.

Lazarus, R. (I99I). Progress on a cognitive motivational relational theory of emotion. American Psychologist, 46(8), 819-834. 
Ledoux, J. (200I). O cérebro emocional: os misteriosos alicerces da vida emocional. Rio de Janeiro: Objetiva. Lennox, R., \& Wolfe, R. N. (I984). Revision of the self monitoring scale. Journal of Personality and Social Psychology, 46(6), I349-1364.

Levy, S. J. (I98I). Interpreting consumer mythology: a structural approach to consumer behavior. Journal of Marketing, 45(3), 49-6I.

Lichtenstein, D., Ridgway, N., \& Netemeyer, R. (I993). Price perception and consumer shopping behavior: field study. Journal of Marketing Research, 30(2), 234-245.

Malhotra, N. K. (200I). Pesquisa de marketing: uma orientação aplicada (3a ed.). Porto Alegre: Bookman. Martineau, P. (1958). The personality of the retail store. Harvard Business Review, 36(I), 47-55.

Mittal, B., Holbrook, M., Beatty, S., Raghuber, P., \& Woodside, A. (2007). Consumer behavior: how humans think, feel, and act in the marketplace. Cincinnati: Open Mentis.

Miyazaky, A. D., Grewal, D., \& Goodstein, R. C. (2005). Effect of multiple extrinsic cues on quality perceptions: a matter of consistency. Journal of Consumer Research, 32(I), 245-253.

Monroe, K. B. (I990). Pricing: making profitable decisions (2nd ed.). New York: McGraw-Hill.

Monroe, K. B., \& Lee, A. Y. (I999). Remembering versus knowing: issues in buyers' processing of price information. Journal of the Academy of Marketing Science, 27(2), 207-225.

Moscovici. S. (1978). A representação social da psicanálise. Rio de Janeiro: Zahar.

Munnukka, J. (2006). Pricing method as a tool for improved price perception. Journal of Revenue and Pricing Management, 5(3), 207-220.

Nagle, T., \& Holden, R. K. (2003). Estratégias e táticas de preços: um guia para as decisões lucrativas. São Paulo: Prentice Hall.

O'Neill, R., \& Lambert, D. (200I). The emotional side of price. Psychology \& Marketing, 18(3), 2I7-237. Peine, K., Heitmann, M., \& Herrmann, A. (2009). Getting a feel for price affect: a conceptual framework and empirical investigation of consumers' emotional responses to price information. Psychology \& Marketing, 26(I), 39-66.

Reynolds, T. J., \& Gutman, J. (I984). Advertising is image management. Journal of Advertising. Armonk, 24(I), 27-37.

Richins, M. L. (I997). Measuring emotions in the consumption experience. Journal of Consumer Research, 24(2), I27-I46.

Rucker, D. D., \& Galinsky, A. D. (2008). Desire to acquire: powerlessness and compensatory consumption. Journal of Consumer Research, 35(2), 257-267.

Sá, C. P. (1996). Sobre o núcleo central das representações sociais. Petrópolis: Vozes.

Samiee, S. (1987). Pricing in marketing strategies of U. S. and foreign-based firms. Journal of Business Research, 15(I), I7-30.

Schuler, M., De Toni, D., \& Milan, G. S. (20I4). New developments in ICM: image configuration method. African Journal of Business Management, 8(6), I80-I90.

Schuler, M., De Toni, D., Milan, G., Panizzon, M., \& Larentis, F. (20I0). As dimensões da imagem de preço para o consumidor: uma abordagem exploratória. Anais do Encontro da Associação Nacional de Pós-Graduação e Pesquisa em Administração, Rio de Janeiro, RJ, Brasil, 34.

Sheth, J. N., Newman, B. I., \& Gross, B. L. (I99I). Consumption values and market choice: theory and applications. Ohio: South Western.

Shipley, D. D., \& Jobber, D. (200I). Integrative pricing via the pricing wheel. Industrial Marketing Management, 30(3), 30I-3I4. 
Simon, H., Bilstein, F. R., \& Luby, F. (2008). Gerenciar para o lucro, não para a participação de mercado. Porto Alegre: Bookman.

Stern, B., Zinkhan, G. M., \& Jaju, A. (200I). Marketing images: construct definition, measurement issue, and theory development. Marketing Theory, 1(2), 20I-224.

Sweeney, J. C., \& Soutar, G. N. (200I). Consumer perceived value: the development of a multiple item scale. Journal of Retailing, 77(2), 203-220.

Sweeney, J. C., Soutar, G. N., \& Johnson, L. (I999). The role of perceived risk in the quality-value relationship: a study in a retail environment. Journal of Retailing, 75(I), 77-IO5.

Theodoridis, P. K., \& Chatzipanagiotou, K. C. (2009). Store image attributes and customer satisfaction across different customer profiles within the supermarket sector in Greece. European Journal of Marketing, 43(5-6), 708-734.

Ting, S. C. (20I2). How need for cognition moderates the influence of country of origin and price on consumer perception of quality. Social Behavior and Personality, 40(4), 529-544.

Tsiros, M., \& Hardesty, D. M. (2010). Ending a price promotion: retracting it in one step or phasing it out gradually. Journal of Marketing, 74(I), 49-64.

Urbany, J. E. (200I). Justifying profitable pricing. Journal of Product \& Brand Management, 10(3), I4I-I59. Vinson, D. E., Scott, J. E., \& Lamont, L. M. (I977). The role of personal values in marketing and consumer behavior. The Journal of Marketing, 41(2), 44-50.

Vorhies, D., \& Morgan, N. (2005). Benchmarking marketing capabilities for sustainable competitive advantage. Journal of Marketing, 69(I), 80-94.

Xia, L., Monroe, K. B., \& Cox, J. (2004). The price is unfair! A conceptual framework of price fairness perceptions. Journal of Marketing, 68(4), I-I5.

Yeung, C. W. M., \& Soman, D. (2007). The duration heuristic. Journal of Consumer Research, 34(3), 3I5-326.

Yuan, H., \& Han, S. (20II). The effects of consumers' price expectations on sellers' dynamic pricing strategies. Journal of Marketing Research, 48(I), 48-6I.

Zaltman, G. (2000). Consumer researchers: take a hike. Journal of Consumer Research, $26(4), 423-442$. Zeithaml, V. A. (I988). Consumer perceptions of price, quality, and value: a means end model and synthesis of evidence. Journal of Marketing, 52(3), 2-22.

Zielke, S. (2006). Measurement of retailers' price images with a multiple-item scale. The International Review of Retail: Distribution and Consumer Research, 16(3), 297-316.

Zielke, S. (20I0). How price image dimensions influence shopping intentions for different store formats. European Journal of Marketing, 44(6), 748-770.

Zielke, S. (20II). Integrating emotions in the analysis of retail price images. Psychology \& Marketing, 28(4), 330-359. 